\title{
Le « baiser Lamourette » (7 juillet 1792)
}

The "Kiss of Lamourette" (7 July 1792)

\section{Caroline Chopelin-Blanc}

\section{(2) OpenEdition}

\section{Journals}

Édition électronique

URL : https://journals.openedition.org/ahrf/10727

DOI : 10.4000/ahrf.10727

ISSN : 1952-403X

Éditeur :

Armand Colin, Société des études robespierristes

Édition imprimée

Date de publication : 1 janvier 2009

Pagination : 73-100

ISBN : 978-2-200-92557-4

ISSN : 0003-4436

\section{Référence électronique}

Caroline Chopelin-Blanc, « Le «baiser Lamourette » (7 juillet 1792)», Annales historiques de la Révolution française [En ligne], 355 | janvier-mars 2009, mis en ligne le 01 janvier 2012, consulté le 23 avril 2022. URL : http://journals.openedition.org/ahrf/10727 ; DOI : https://doi.org/10.4000/ahrf. 10727 


\title{
LE «BAISER LAMOURETTE » (7 JUILLET 1792)
}

\author{
Caroline CHOPELIN-BLANC
}

\begin{abstract}
Le 7 juillet 1792, Adrien Lamourette, évêque constitutionnel et député de Rhône-et-Loire, prononce à la tribune de la Législative un discours appelant à l'union autour de la Constitution de 1791. Ses propos suscitent des embrassades. Cet épisode, souvent moqué sous le nom de "baiser Lamourette », est resté négligé par l'historiographie. Comment expliquer qu'au sein d'une Assemblée alors au bord de la rupture, l'intervention d'un député peu doué de talents oratoires déclenche une telle réconciliation, certes éphémère ? Les interprétations contemporaines de l'événement sont contradictoires : les acteurs seraient guidés tantôt par une véritable volonté de paix, tantôt par la duplicité. Les écrits de Lamourette apportent une lumière nouvelle et révèlent comment, sous la pression des événements, l'orateur lui-même en vient progressivement à modifier son interprétation de l'épisode.
\end{abstract}

Mots-clés : Adrien Lamourette, Assemblée législative, Constitution, émotion politique.

Même s'il conserve une notice dans la plupart des dictionnaires, le nom d'Adrien Lamourette n'évoque plus grand chose aujourd'hui ${ }^{1}$. Au mieux se rappelle-t-on, en esquissant un sourire, le « baiser Lamourette », cette scène de réconciliation générale des députés provoquée par un discours de Lamourette appelant à l'union autour de la Constitution, lors de la séance du 7 juillet 1792, en plein débat sur la « patrie en danger ». Le

(1) Caroline Blanc-Chopelin, De l'apologétique à l'Église constitutionnelle: Adrien Lamourette (1742-1794), Université Jean Moulin Lyon 3, thèse sous la dir. de Bernard Hours, 2006, 2 volumes, $763+753$ p. ; Edna H. Lemay (dir.), Dictionnaire des législateurs, 1791-1792, FerneyVoltaire, Centre international d'étude du XVIII ${ }^{\mathrm{e}}$ siècle, 2007, t. 2, p. 459-461. 
surnom populaire donné à cette scène et, plus généralement, le patronyme même de son auteur, de surcroît un ecclésiastique, n'incitent pas à prendre au sérieux le personnage. Pourtant, au vu de son itinéraire, il apparaît comme ayant joué un rôle non négligeable pendant les premières années de la Révolution.

À partir de la fin août 1791, Adrien Lamourette cumule la fonction d'évêque constitutionnel de Rhône-et-Loire et de métropolitain du SudEst, à laquelle il a été élu le $1^{\text {er }}$ mars, avec la charge de député de Rhôneet-Loire. Cette élection à la Législative s'explique par la popularité qu'il a acquise depuis son arrivée à Lyon et surtout par la recommandation en sa faveur adressée par Mirabeau aux sociétés populaires lyonnaises. Lamourette et le tribun révolutionnaire ont en effet tissé des liens étroits pendant leur courte collaboration (deuxième semestre 1790-hiver 1791), le premier servant au second de «théologien » et lui fournissant notamment le canevas de deux discours importants prononcés à la tribune de la Constituante : le Discours sur l'exposition des principes de la Constitution civile du clergé, le 26 novembre 1790, et le Projet d'adresse sur la Constitution civile du clergé, le 14 janvier 1791. Cette adhésion de Lamourette à la Révolution peut d'abord surprendre au regard de son itinéraire antérieur. Né dans l'Artois en 1742, il entre à 17 ans dans la Congrégation de la Mission fondée par Vincent de Paul. Il suit sa formation chez les lazaristes, devient professeur dans les séminaires lorrains de la Congrégation et dirige même le séminaire de Toul pendant deux années (1776-1778). Mais en 1778, une première césure se produit dans son itinéraire : il démissionne de son poste de directeur de séminaire, demande un congé de la Congrégation et s'occupe pendant cinq ans de la cure rurale d'Outremécourt en Lorraine. En 1783, intervient une deuxième césure : il rompt définitivement avec la Congrégation de la Mission. En 1785 , il entame une carrière d'apologiste. Ses deux premiers ouvrages lui valent d'être remarqué par l'archevêque de Paris, $\mathrm{M}^{\mathrm{gr}}$ Leclerc de Juigné, qui le nomme alors aumônier de l'abbaye royale des Perrines de Chaillot. À la veille de la Révolution, en mai 1789, il obtient le privilège pour son dernier ouvrage apologétique, les Pensées sur la philosophie de la foi. Puis il fréquente les milieux favorables à la Révolution, tels que la Confédération des amis de la vérité ou le salon de Madame Helvétius, où il rencontre Mirabeau. Au même moment, il renoue avec l'abbé Grégoire, son ancien élève à Metz. Ainsi, d'apologiste, ce qui implique une contestation, sinon un rejet, des idées soutenues par les philosophes des Lumières, Lamourette devient un partisan de la Révolution qui, elle, se déclare ouvertement l'héritière de ces mêmes philosophes. 
Comment devient-il révolutionnaire ? La réponse est à rechercher pour partie dans ses conceptions religieuses, qui se dessinent dès avant 1789, et pour partie dans l'opportunité, offerte par la Révolution, de jouer un rôle de poids dans le clergé. Son christianisme "éclairé » mettant l'accent sur la vocation humaine au bonheur, sa théologie du devenir fondée sur le concept d'énergie et sa compréhension optimiste de l'homme, capable de suivre le message du Christ, constituent un terreau favorable à l'accueil des idées révolutionnaires et du catholicisme épris de liberté et d'égalité qui s'affirme ouvertement à partir de 1789. Une interaction se produit : certaines de ses intuitions théologiques s'approfondissent au contact des idées révolutionnaires, et inversement les idées religieuses de Lamourette font naître chez lui une appréhension bien particulière de la Révolution. La Révolution est l'occasion pour lui d'assumer des responsabilités et d'accomplir une mission qu'il considère comme divine : concilier la Révolution et le christianisme. Son élection successive à l'évêché lyonnais et à l'Assemblée législative lui permet de travailler activement à ce projet.

Au sein de l'Assemblée législative, il prend plutôt rarement la parole. Il prétend travailler en sous-main. Pour justifier sa discrétion, il invoque son statut d'ecclésiastique et ses piètres talents d'orateur : « J'ai rarement parlé à la tribune ; mais de grands et énergiques patriotes y ont souvent prononcé ce que j'avais conçu et écrit. J'ai pensé que des idées d'une certaine nature, articulées par eux, fixeroient plus l'attention, et produiroient plus d'effet, que si elles eussent été présentées par un homme de mon état $\rangle^{2}$. Il intervient toutefois le 21 novembre 1791, en faveur de la défense du titre de constitutionnel et du statut de fonctionnaire public attribués aux ministres assermentés : son discours, bien accueilli, est mis à l'impression. Ses autres prises de parole, très brèves, concernent des questions mineures, comme les avances à faire à la Maison de secours de Paris (le 30 mars 1792) et la remise d'un don de la part de la commune d'Écully près de Lyon (le 20 juin). Aussi l'exaltation qu'entraîne son discours du 7 juillet 1792 peut-elle paraître d'autant plus étonnante qu'elle est suscitée par un député peu renommé pour son charisme. À la suite de Timothy Tackett, ne peut-on pas souligner, à travers le cas de Lamourette, le rôle moteur que peuvent

(2) Adrien Lamourette, Réponse de M. Lamourette, évêque de Lyon, à M. l'abbé Molin, son $2^{e}$ vicaire, au sujet des calomnieuses imputations qu'on a méchamment répandues dans cette ville contre cet évêque, vrai ami de la Patrie, député de la $2^{e}$ législature, Lyon, Pélisson, s. d. [1792], p. 8. 
acquérir, par un discours décisif, des députés peu connus face à des orateurs plus chevronnés habituellement plus favorisés par l'historiographie ${ }^{3}$ ?

Cette scène $\mathrm{du}$ 《 baiser Lamourette » provoque sourires et interrogations. Un tour d'horizon de l'historiographie prouve que le «baiser » n'a pas été totalement négligé, sans être toutefois soumis à une analyse approfondie. De plus, les interprétations exprimées sont loin d'être monocordes sur sa signification. Certains minimisent l'événement en le rabaissant à l'ordre de l'anecdote. Ils l'assimilent à une " idylle " ${ }^{4}$ ou à une plaisanterie qui aurait permis d'égayer les Français en un moment particulièrement tendu ${ }^{5}$. D'autres historiens s'attardent sur sa signification. Dans son Histoire de la Révolution, Adolphe Thiers croit en la sincérité de la réconciliation : selon lui, les députés profitent du discours de Lamourette pour suspendre leurs divisions et se réfugier dans le confort d'un présent conciliateur. Placé dans une perspective plus longue, le « baiser » permet d'éclairer les raisons de l'aspiration à la république. Il prouve que le 7 juillet 1792 , soit seulement un mois avant la fin de la monarchie constitutionnelle, la république était perçue par ses promoteurs, non comme le régime idéal mais comme une simple solution de rechange ${ }^{6}$. De son côté, Jules Michelet a du mal à livrer une interprétation de la scène de réconciliation du 7 juillet, qu'il date par erreur du 6 juillet: "Chose étrange et inexplicable », s'exclame-t-il au constat de l'enthousiasme qui saisit une Gironde alors bien hostile au trône. Plus loin, il conclut sa narration : "Quoi qu'il en soit, la scène fut bizarre autant qu'imprévue ». Finalement, selon sa vision d'une France dotée d'une personnalité propre, quasi mystique parfois, il explique que « ces effusions naïves ne doivent pas surprendre. La France est un pays où le bon cœur éclate par accès, dans les plus violentes discordes ${ }^{7}$. Dans son Histoire de la Révolution française, Louis Blanc, favorable aux Jacobins mais ne reprenant pas ici l'interprétation immédiate du club, lit l'épisode selon sa grille personnelle et téléologique d'interprétation du sens de l'histoire. Même bref, le « baiser» conforte son idée selon laquelle « le cœur de l'homme

(3) Timothy Tackett, Par la volonté du peuple. Comment les députés de 1789 sont devenus révolutionnaires [1996], Paris, Albin Michel, 1997, p. 214-222.

(4) Pierre de La Gorce, Histoire religieuse de la Révolution française, Paris, Plon, 1912, tome II, p. 226.

(5) Louis-Pierre Anquetil, Histoire de France depuis les Gaulois jusqu'à la fin de la Monarchie, Paris, Ledentu, 1825 (5 éd.), volume 11, p. 362.

(6) Adolphe Thiers, Histoire de la Révolution, Paris, Furne, Jouvet et Compagnie, 1870, tome 2, p. 172.

(7) Jules Michelet, Euvres de J. Michelet. Histoire de la Révolution française, Paris, A. Lemerre, 1888, tome IV, livre IV, p. 317-318. 
n'est point fait pour la haine » et que le terme ultime de l'histoire consiste en la réunion fraternelle de toute l'humanité ${ }^{8}$. Jean Jaurès attribue de son côté des « arrière-pensées » à l'orateur. Il insère l'épisode dans son interprétation globale de la Révolution qui, selon sa vision d'une démocratie sociale et républicaine, ne s'accomplit pas en 1789 mais en $1793^{\circ}$. Dans ce schéma dualiste, Lamourette est plutôt rangé dans le mauvais camp, en l'occurrence celui qui conçoit la monarchie constitutionnelle comme le point d'arrêt de la Révolution. Édouard Herriot atténue cette interprétation dans Lyon n'est plus. Il qualifie la scène de réconciliation de «triomphe pour Lamourette - et d'ailleurs un triomphe contre la République $»^{10}$.

Aussi, pour ces historiens, le « baiser » est-il connoté tantôt positivement, comme dévoilant le sens de l'histoire ou la personnalité inhérente à la France, tantôt négativement, comme émanant d'un orateur exclu du panthéon de la République. Plus récemment, le «baiser » a été étudié dans le cadre de travaux portant sur la sensibilité révolutionnaire et sur le discours des Assemblées révolutionnaires. Pierre Trahard mentionne le « baiser » comme l'un des points d'orgue de la sensibilité révolutionnaire ${ }^{11}$. Quant à Robert Darnton, qui évoque le «baiser» en introduction d'un ouvrage intitulé The Kiss of Lamourette, il exprime son désarroi face à cet épisode : est-ce la reconstitution du baiser médiéval de l'amour ou bien un rituel pour clore une guerre civile, un souffle du sentiment préromantique perceptible dans les tableaux de Greuze, une victoire momentanée d'Éros sur Thanatos, ou enfin une brève bataille gagnée dans quelque coin obscur de l'âme ? Plus avant, l'auteur rapproche l'enthousiasme qui soulève les députés d'une explosion de type millénariste ${ }^{12}$. L'historiographie récente essaie davantage de rendre au réel sa complexité et par là, a paradoxalement brouillé l'interprétation du « baiser Lamourette».

Comment donc expliquer un tel enthousiasme dans l'enceinte parlementaire? Dans quel contexte s'inscrit-il : quelles sont les tensions politiques qui habitent alors l'Assemblée, et auxquelles cet épisode

(8) Louis Blanc, Histoire de la Révolution française, Paris, Lacroix, 1869, tome VI, p. 420 .

(9) Jean JAURÈs, Histoire socialiste de la Révolution française, Paris, Éditions sociales, 1970, tome I, p. 633-634 : «Il ne s'agissait pas de savoir si, de parti pris et par système, les uns voulaient les deux Chambres et les autres la République. Il s'agissait de savoir si, pour sauver la royauté, on était prêt à compromettre la Révolution, ou si, pour sauver la Révolution, on était prêt à perdre la royauté $»$.

(10) Édouard Herriot, Lyon n'est plus. Jacobins et modérés, Paris, Hachette, 1937, p. 62.

(11) Pierre Trahard, La sensibilité révolutionnaire (1789-1794), Paris, Boivin, 1936, p. 50.

(12) Robert Darnton, The Kiss of Lamourette. Reflections on Cultural History, New-York, Norton, 1990, p. XIV puis p. 12. Le « baiser Lamourette » est en fait assez peu étudié en lui-même. 
permet de faire contrepoids? Concernant l'orateur, quelles sont les motivations profondes de son intervention ? Croit-il réellement à la viabilité de la Constitution? Les écrits de Lamourette permettent d'apporter une lumière nouvelle, surtout quant au regard qu'il jette lui-même sur l'événement. Ils exigent de prendre en compte le facteur chronologique qui modifie l'interprétation que l'orateur livre de sa propre allocution.

\section{Une intervention efficace : l'émotion politique partagée à l'Assemblée}

À compter du 20 juin, les tensions ne cessent de s'exacerber. Le 28, La Fayette se présente devant l'Assemblée pour réclamer la mise hors la loi des clubs et tente le lendemain de faire marcher la garde nationale contre les Jacobins. Ce coup de force échoue. La Fayette regagne son quartier général à la frontière, provoquant l'exaspération des militants révolutionnaires parisiens qui le brûlent en effigie. Aux Tuileries, le roi fait de plus en plus figure de prisonnier. Sur les fronts extérieurs, l'armée française, officiellement engagée depuis le 20 avril 1792 contre l'empereur d'Autriche et le roi de Prusse, accumule les revers. Le 30 juin, l'Assemblée émet un décret réglant les formes de la déclaration de la patrie en danger. Tour à tour, Torné, Pastoret et Condorcet exposent leur opinion. Les débats sont de plus en plus tendus : les députés sont conscients de faire face à une crise politique majeure et redoutent les réactions des sections parisiennes. Le 7 juillet au matin, tandis que le président est sur le point d'accorder la parole à Brissot au sujet des mesures de sûreté générale, Lamourette demande à faire une motion d'ordre à ce propos. Il promeut l'unité autour de la Constitution et met en garde à la fois contre la république et contre le bicamérisme. Outre le contenu même de l'allocution, il faut analyser ses conséquences immédiates à l'Assemblée, car ce discours provoque d'emblée une exaltation sans précédent parmi les députés depuis 1789.

Lors de son intervention, Lamourette souligne l'inanité des mesures prises par l'Assemblée pour enrayer « les progrès des maux, des divisions et des fermentations qui déchirent le sein de cet empire ». Les malheurs de la France proviendraient de la " désunion de l'Assemblée nationale ». En conséquence, il invite les députés à dépasser leurs dissensions, à reconnaître en chacun d'eux « la probité » et «l'honneur », et finalement à « ramene[r] la représentation nationale à l'unité ». Il réduit les désaccords à un « malentendu » :

«Une section de l'Assemblée Nationale attribue à l'autre le dessein séditieux de renverser la monarchie, et d'établir la république ; et celle-ci 
prête à la première de vouloir l'anéantissement de l'égalité constitutionnelle, et de tendre à la création de deux chambres ; voilà le foyer désastreux d'une désunion qui se communique à tout l'empire, et qui sert de base aux coupables espérances de ceux qui manœuvrent la contre-révolution ».

Puis il invite ses collègues :

«Foudroyons, Messieurs, par une exécration commune, et par un dernier et irrévocable serment, foudroyons et la république et les deux chambres ; jurons-nous fraternité réelle, confondons-nous en une seule et même masse d'hommes libres, également redoutable à l'esprit d'anarchie et à l'esprit féodal : et le moment où nos ennemis domestiques et étrangers ne pourront plus douter de ce que nous voulons une chose fixe et précise, et que ce que nous voulons, nous le voulons tous, sera le véritable moment où il sera vrai de dire que la liberté triomphe et que la France triomphe ».

Finalement, il propose la motion que « ceux qui rejettent et haïssent également et la république et les deux chambres se lèvent $\gg{ }^{13}$.

Son intervention mobilise trois concepts politiques : la Constitution, la république et le système des deux chambres. Lamourette appelle à l'union autour de la Constitution à un moment où celle-ci est fortement fragilisée. Depuis son avènement, son application est perturbée. En effet, la Constitution voit s'opposer en son sein deux ressorts : d'une part, la souveraineté nationale incarnée par l'Assemblée nationale ; d'autre part, les libertés naturelles de l'individu telles qu'elles sont inscrites dans la Déclaration des droits de l'homme et desquelles finissent par se réclamer les partisans du veto royal, surtout après l'épisode de Varennes et l'accaparement de la souveraineté par l'Assemblée. En 1792, la polémique sur la sanction royale s'amplifie. Elle s'élargit à un débat sur la légitimité générale de la sanction opposée à la souveraineté ${ }^{14}$. Or, à la charnière des mois de juin et de juillet, la discussion bat son plein à un moment où Louis XVI refuse de retirer son veto à propos de la suppression de sa garde personnelle et de la déportation des prêtres réfractaires. Ainsi, l'intervention de Lamourette constitue un ultime sursaut de l'Assemblée tandis que la viabilité de la Constitution est fortement mise en doute.

(13) Projet de réunion entre les membres de l'Assemblée nationale, par M. Lamourette, Député du Département de Rhône-et-Loire, imprimé par ordre de l'Assemblée nationale, Paris, de l'Imprimerie Nationale, 1792.

(14) François Furet et Ran Halevi, La monarchie républicaine. La constitution de 1791, Paris, Fayard, 1996, p. 163-170 et 240-252. 
Le terme de république est employé péjorativement par Lamourette. Considéré comme générateur de l'« esprit d'anarchie », il est par conséquent identifié à la licence et à l'absence de toute règle morale et religieuse. En juillet 1792, ce vocable employé dans le sens d'organisation politique d'un État où le pouvoir, non héréditaire, est exercé par les représentants de la population, ne bénéficie pas encore d'une faveur unanime. Il faut attendre septembre 1792 pour qu'il cesse de désigner une abstraction et devienne une réalité tangible. Son utilisation connaît d'abord une première étape d'intensification en juin 1791 : jusqu'alors employé prudemment, circonscrit par exemple au Cercle social où Condorcet dresse l'apologie de la république le 8 juillet 1791, il bénéficie d'un usage plus fréquent après la fuite du roi qui avive les sentiments républicains ${ }^{15}$. Le Club des cordeliers ou les sociétés patriotiques et populaires sont représentatifs de ce courant duquel se méfient l'Assemblée et le Club des jacobins. Toutefois, à partir du printemps 1792, le vocable se répand. La réflexion sur les modalités d'application du régime républicain s'approfondit. En effet, la guerre accélère le processus de déconsidération de la monarchie constitutionnelle déjà paralysée dans son fonctionnement interne et incapable de remédier à la crise économique. Finalement, le terme de république en vient à désigner successivement une revendication politique et un régime politique susceptible de devenir la pièce de rechange d'une monarchie constitutionnelle exténuée ${ }^{16}$. Les écrits de Thomas Paine, héraut de la République américaine et des droits naturels en Europe, alimentent considérablement cette réflexion. Le discours de Lamourette reflète donc le changement de statut de la république, considérée non plus comme une simple abstraction mais comme un régime politique alternatif, idée qui, émanant des sociétés politiques, pénètre progressivement l'enceinte parlementaire. À la date du 7 juillet 1792, l'orateur reste encore attaché à la fonction royale et n'envisage pas la substitution de la république à la monarchie constitutionnelle.

De même, il rejette l'évolution du système parlementaire vers le modèle anglais, caractérisé par l'existence de deux chambres. Il associe le bicamérisme à « l'esprit féodal », donc à une régression de la souveraineté

(15) Mona Ozouf, Varennes. La mort de la royauté (21 juin 1791), Paris, Gallimard-NRF, 2005, p. 226-263 ; Marcel DorignY, « La République avant la République. Quels modèles pour quelle République ? », dans Michel Vovelle (dir.), Révolution et République. L'exception française, Paris, Kimé, 1994, p. 109-119.

(16) Gérard Maintenant, «République (mai 1789-septembre 1792)», Dictionnaire des usages socio-politiques. II. Les notions-concepts, Paris, Klincksieck, 1987, p. 99-115. 
populaire. Cette critique vise surtout la chambre des Lords, dont les membres, issus de l'aristocratie, sont nommés par le monarque. Durant les dernières années de l'Ancien Régime, et jusqu'en 1792, la constitution britannique exerce des influences contraires sur l'opinion française, mêlant à la fois attraction et rejet ${ }^{17}$. À la veille de la Révolution, deux attitudes opposées se dessinent. D'un côté, sensibilisés à la conception démocratique du gouvernement américain et approuvant l'agitation réformiste d'Outre-Manche, certains écrivains, comme Condorcet ou Brissot, présentent l'Angleterre comme un pays privé de la véritable liberté politique. De l'autre côté, Mirabeau, l'abbé Morellet ou encore Mallet du Pan, dressent l'éloge de la monarchie mixte anglaise, qui permettrait de garantir la stabilité de l'État grâce à l'équilibre des pouvoirs et de protéger les droits individuels grâce au système représentatif. En juin 1789, la constitution anglaise tend donc à s'imposer comme le modèle politique dominant. Après le 14 juillet 1789, les monarchiens emmenés par Mounier défendent le système parlementaire anglais. Mais les votes des 10 et 11 septembre consacrent la défaite de leur programme constitutionnel. La coalition de partis extrêmes, englobant des absolutistes intransigeants, des petits nobles attachés à l'esprit de caste et des démocrates aux revendications égalitaires, a signé l'échec de la greffe du bicamérisme en France.

$\mathrm{Au}$ printemps 1791, sous l'impulsion de Barnave, Duport et Lameth, chefs de file des feuillants, l'idée d'implanter la constitution britannique renait, avec pour objectif cette fois, de contrer le progrès des forces démocratiques et de restaurer l'autorité monarchique. Mais la constitution du 13 septembre 1791 instaure une chambre unique. De manière générale, le régime anglais, qualifié d'aristocratique, connaît une forte dévaluation dans l'opinion, au moment où parallèlement la République américaine conquiert des suffrages. Toutefois, quelques partisans du bicamérisme à l'anglaise subsistent. Certains envisagent de modifier sa composition, à l'instar de La Fayette qui, hostile à la pairie, propose de mettre en place deux chambres électives. Le 27 mai, dans L'Indicateur ou Journal des causes et des effets, périodique qu'il vient de fonder une semaine auparavant pour défendre le programme feuillant, Adrien Duport, le chef des feuillants, insère un vibrant éloge de la constitution britannique et vitupère contre ses détracteurs ${ }^{18}$. Au moment où Lamourette s'exprime,

(17) Gabriel Bonno, La constitution britannique devant l'opinion française de Montesquieu à Bonaparte, Genève, Slatkine, 1970, p. 152-275.

(18) Ibid., p. 256. Voici quelques propos de Duport: «Depuis que les ridicules discussions des clubs et des pamphlets nous ont donnés [sic] une sorte de jargon, nous parlons avec un souverain 
le système des deux chambres principalement symbolisé par le régime anglais dispose certes d'une image dégradée dans l'opinion mais ne possède pas moins d'ardents défenseurs dans les milieux politiques et journalistiques.

Lamourette s'oppose donc aux deux régimes politiques qui pourraient remplacer la monarchie constitutionnelle. Dans sa perspective, le dysfonctionnement de la Constitution ne provient pas de défauts consubstantiels à celle-ci mais à sa mauvaise mise en œuvre par les acteurs politiques, et en premier lieu par l'Assemblée. C'est pourquoi il invite les députés à la soutenir unanimement.

Le discours suscite aussitôt de vives réactions. D'abord au cours même de sa proclamation. Des applaudissements s'élèvent quand Lamourette définit la probité et l'honneur comme points de rencontre entre deux personnes d'avis divergents; des approbations « oui, oui, nous ne voulons que la constitution » fusent à son invitation à prêter serment contre la république et les deux chambres; enfin de vibrants applaudissements saluent ses dernières phrases. L'émotion politique de la salle, émanant à la fois des bancs parlementaires et des tribunes, explose surtout à la fin de l'intervention $^{19}$. Les députés se lèvent, s'embrassent, jurent de préserver la Constitution : « M. Mathieu Dumas embrasse M. Albitte, M. Dubois-de-Bellegarde presse sur son sein M. Viénot-Vaublanc, MM. Merlin, Fauchet, Emery serrent dans leurs bras MM. Jaucourt, Ramond et Chéron-La-Bruyère ». Les spectateurs, également enthousiastes, lancent des acclamations ${ }^{20}$. Toute différence politique est abolie. L'unité parlementaire autour de la Constitution prévaut. Elle apparaît alors comme la mesure la plus efficace pour assurer la défense de la patrie. Cette scène de réconciliation générale ${ }^{21}$, extraordinaire, perturbe complètement le déroulement normal de la séance. Elle interrompt la programmation des interventions des députés. Brissot demande à surseoir son allocution au lendemain afin de « ne pas perturber la réunion fraternelle qui vient de s'opérer ». Un député, Rühl, réclame

(suite de la note $18 \mathrm{p} .81$ )

mépris de la Constitution anglaise. Jamais il n'est arrivé à aucun de nos écrivains modernes de la juger sur ses effets, mais on la compare à je ne sais quelle niaiserie de principes que l'on a mis dans sa tête [...]. » (L'Indicateur..., $\mathrm{n}^{\circ}$ 8, 27 mai 1792).

(19) Sur les précédents «émotionnels » au sein de l'Assemblée législative en juin 1792, voir Sophie WAHNICH, «L'émotion en partage : l'Assemblée législative face aux dangers de la patrie (juin 1792) », dans Éric Nogel et Jean-Paul SERmain (dir.), Une expérience rhétorique : l'Éloquence de la Révolution, Oxford, Voltaire Foundation, 2002, p. 89-101.

(20) Archives parlementaires, tome 46, p. 212 (séance du 7 juillet 1792).

(21) Pierre-Célestin Roux (dir.), Histoire parlementaire de la Révolution française, ou journal des assemblées nationales depuis 1789 jusqu'en 1915, Paris, Paulin, 1834, tome 15, p. 335. 
même que l'Assemblée adopte un décret par lequel serait considéré comme « perturbateur du repos public » tout journaliste qui « jetter[ait] du louche » sur la scène ; mais cette proposition est repoussée. La discussion s'oriente ensuite vers un point technique, susceptible de ne pas rompre l'harmonie parlementaire : le mode de constat de l'état-civil.

L'enjeu est alors de donner le plus large écho à cette réconciliation afin qu'elle entraîne dans son sillage une unité nationale. Il s'agit donc d'avertir les différentes autorités. D'abord le roi, détenteur du pouvoir exécutif selon le texte de la Constitution. Le président de l'Assemblée propose de lui envoyer une députation, conduite par Lamourette lui-même. Puis, sur les sollicitations de Bazire et de Carnot le jeune, il est décrété que tous les corps administratifs et judiciaires de Paris assisteront à la séance du soir, afin que lecture leur soit faite du procès-verbal du matin, à charge pour eux de le répercuter ensuite auprès de la population ${ }^{22}$. Cette mesure vise à calmer les tensions qui agitent la capitale. En effet, la veille, le 6 juillet, le directoire du département a ordonné la suspension du maire Pétion, l'un des brissotins les plus en vue, ainsi que du procureur de la Commune, Manuel, accusés par le roi et le département de Paris d'avoir favorisé l'émeute et l'invasion des Tuileries lors de la journée du 20 juin $^{23}$. Cette décision, qui accroît plus encore la popularité de Pétion, grossit le mécontentement des Parisiens. Enfin, dernière mesure pour répercuter l'enthousiasme parlementaire, l'Assemblée décide l'impression du discours de Lamourette et son envoi dans tous les départements. Le roi se présente à la salle des Manèges sitôt qu'il est informé officiellement par les vingt-quatre députés délégués auprès de lui. D'après le ministre de la Justice Dejoly, le roi entend profiter de cette manifestation d'enthousiasme pour se rapprocher de l'Assemblée ${ }^{24}$. Louis XVI proclame à son tour : « La constitution doit être le point de ralliement de tous les Français ; nous devons tous la défendre ; le roi leur en donnera l'exemple ». Après son départ, la séance est levée.

À partir de ce moment, l'émotion politique retombe et fait place à la froideur, voire à la peur. La Société des jacobins répandrait dès le jour même un « esprit de violence », outragerait et menacerait les députés qui gagnent l'enceinte parlementaire pour la séance du $\operatorname{soir}^{25}$. Celle-ci

(22) Ibid., p. 337-338.

(23) Marcel Dorigny, «Pétion Jérôme, dit de Villeneuve », dans Albert Soboul (dir.), Dictionnaire historique de la Révolution française, Paris, PUF, 1989, p. 838-840.

(24) Jacques Godechot (éd.), « Mémoires d'Étienne-Louis-Hector Dejoly », Annales historiques de la Révolution française, tome 18, 1946, p. 328.

(25) Histoire de la Révolution de France, précédée de l'exposé rapide des Administrations successives qui ont déterminé cette Révolution mémorable, Paris, Bidault, 1796, p. 65. 
contraste totalement avec celle du matin. La lecture du procès-verbal aux corps administratifs, judiciaires et municipaux de Paris ne soulève aucun enthousiasme. Le président rappelle ensuite la suspension du maire et entame l'ordre du jour ${ }^{26}$. Vraisemblablement l'affaire Pétion a joué un rôle fondamental dans l'étouffement de l'émotion politique. C'est elle qui monopolise l'attention et non la scène de réconciliation dont justement elle paraît souligner la fragilité, voire l'hypocrisie. Finalement l'émotion politique se révèle brève et circonscrite : elle se limite surtout à l'enceinte parlementaire et ne dure que quelques heures.

Comment expliquer la naissance d'une telle exaltation ? Préalablement, il faut nuancer l'unicité de cette explosion d'enthousiasme. Par exemple, la nuit du 4 août 1789 fut également marquée par une telle effervescence de sentiments. À l'instar de cette fameuse séance, l'épisode du «baiser Lamourette » constitue un apogée de l'émotion politique pendant la Révolution. Des événements similaires mais de moindre intensité se déroulent lors de la prestation de serment par les députés de la Législative au début d'octobre 1791 ou bien le 8 juillet 1792 à l'énoncé des premiers mots d'une pétition en faveur de Pétion. Il ne s'agit pas ici de s'appesantir sur les portées et les contextes différents de chacune de ces séances mais de souligner la périodicité des scènes effusives à l'Assemblée. L'exaltation du 7 juillet 1792 peut s'expliquer en partie par le contexte de crise. Elle apparaitrait comme un moment d'exutoire alors que depuis le 20 juin s'accroît le divorce entre le principe monarchique et le droit issu de la Révolution et que, depuis le 30 juin Vergniaud, Condorcet et leurs amis pressent leurs collègues de déclarer la patrie en danger.

La « sensibilité révolutionnaire » peut également apporter un élément d'explication. Héritière d'un XVIII siècle qui exalte la nature de l'être sensible, marquée par une forte propension à l'attendrissement ${ }^{27}$, elle s'appuie sur l'éloquence conçue à la fois comme une arme et un moyen de séduction. L'événement du 7 juillet montre combien l'Assemblée légis-

(26) Pierre-Célestin Roux (dir.), op. cit., tome 15, p. 340-342. Quelques mots sont révélateurs de l'atmosphère de la réception des corps de Paris lors de la séance du soir : « Toute la cérémonie fut très froide; les visiteurs ne prononcèrent pas un mot».

(27) Au sujet des dimensions multiples prises par le baiser au XVIII ${ }^{\mathrm{e}}$ siècle, particulièrement dans l'art et la littérature, se reporter aux contributions réunies par Alain MonTANDON, Les baisers des Lumières, Clermont-Ferrand, Presses Universitaires Blaise Pascal, 2004. Seule l'étude de Carole Dornier, intitulée « Le baiser dans la tourmente révolutionnaire : effusions et épanchements d'une aristocratie victime », est consacrée au baiser pendant la Révolution. S'appuyant sur les écrits de la duchesse de Tourzel, de Madame Campan et de la baronne d'Oberkirch, l'auteur s'attache à montrer que le baiser traduit chez ces femmes mémorialistes la «nostalgie d'un temps révolu » et le « repli sur la sphère privée » face aux bouleversements révolutionnaires. 
lative est dominée par les forces affectives qui agissent tant au niveau de l'orateur que de l'auditoire. Bien sûr, l'effet de contagion de l'émotion joue également. Sur le moment, le « baiser Lamourette » revêt une valeur réelle de réconciliation ${ }^{28}$, dénuée de calculs politiques. Pour preuve, la motion, certes rejetée, de Rühl. De même, l'étude de l'outillage mental largement hérité du XVIII ${ }^{\mathrm{e}}$ siècle éclaire la compréhension de l'exaltation générale qui saisit l'Assemblée le 7 juillet au matin. En effet, les effusions sont guidées par la volonté, sinon l'obsession, de retrouver l'unitée, concept associé à celui d'indivisibilité et omniprésent dans nombre d'écrits révolutionnaires, en premier lieu chez Lamourette ${ }^{30}$. En 1792, les contemporains ont encore des difficultés à penser la séparation et le pluralisme.

Ainsi, le discours prononcé par Lamourette le 7 juillet 1792 jouit dans l'immédiat d'une réception exceptionnelle. L'émotion politique atteint un degré extrême qui rappelle les scènes émouvantes des premiers mois de la Révolution. Elle est provoquée non seulement par le contenu laconique et conciliateur du discours, mais par des facteurs extrinsèques, tels que le contexte et la disposition des acteurs politiques. Mais elle s'évanouit rapidement. Dès le soir, les tensions sont ravivées, principalement du fait de la suspension de Pétion contestée par les sections parisiennes. Le lendemain, l'exaltation est complètement retombée. Des regards différents sont jetés sur l'épisode de la veille.

\section{La réception du « baiser Lamourette » : baiser de paix ou baiser de Judas?}

L'épisode du «baiser Lamourette » est reçu en deux temps : les réactions dans les jours qui suivent l'événement, cette fois-ci à l'extérieur de l'enceinte parlementaire; puis les opinions formulées dans les mémoires ou les écrits à prétention historique des contemporains, qui bénéficient de davantage de recul pour mûrir leur jugement. L'interrogation qui traverse généralement les opinions tient en quelques mots : sincérité ou cynisme de l'orateur et des députés ?

(28) Pierre Trahard, op. cit., p. 31-34 sur l'importance de l'héritage du XVIII ${ }^{\mathrm{e}}$ siècle dans la formation de la sensibilité révolutionnaire, p. 176 sur le rôle de la parole, et p. 50 sur l'analyse du « baiser Lamourette ».

(29) Anne Vincent-Buffault, Histoire des larmes, Paris, Rivages, 1986, p. 91.

(30) Jean-René Suratteau, « Unité/indivisibilité », Albert Soboul (dir.), Dictionnaire historique de la Révolution française, op. cit., p. 1060-1061. L'unité est d'abord le dogme des Constituants. Puis à partir de 1792, la question de l'unité est liée au débat sur le sens du terme patrie, les patriotes étant considérés comme les défenseurs de la liberté et de l'intégrité du territoire. 
Les jours suivant le 7 juillet, l'épisode du « baiser Lamourette » connait d'abord un accueil plutôt favorable dans quelques milieux. Des sections de la capitale saluent la réconciliation en organisant un banquet ${ }^{31}$. À Lyon, le 12 juillet, le directoire du département tient une réunion dans l'esprit du « baiser » en présence des districts de la ville et de la campagne ainsi que des municipalités de Lyon, Vaise, Cuire-la Croix Rousse. Mais il n'obtient pas la réconciliation souhaitée en raison des débats autour de la notion de république ${ }^{32}$. De manière générale, le «baiser » n'entraîne pas de réels prolongements. Il reçoit cependant un large écho dans la presse. Cette réconciliation intrigue les journalistes, qui livrent des interprétations fort variées.

Le Patriote français de Brissot publie dans le numéro du lendemain un article relatant la scène d'enthousiasme. Le papier se termine par une conclusion nuancée sur cette «fermentation » qui tend à embrouiller le jugement mais qui pourrait s'avérer salvatrice si elle permettait de prolonger l'union. Le doute sur la sincérité de la scène pèse ici moins sur l'orateur, dont la franchise n'est à aucun moment mise en cause, que sur les acteurs de cette unité ${ }^{33}$. Le 9 juillet, le Patriote français consacre encore un article au même sujet, plus précisément à la diversité des réactions qu'a suscitée l'événement. Il résume assez bien les diverses positions :

«La réunion des députés est loin d'avoir produit la même sensation au dehors qu'au-dedans. Les uns la regardent comme une comédie jouée par les intriguans ; d'autres attendent pour juger, mais veillent plus activement que jamais ; d'autres ne veulent point se fier à ces conversions d'un jour. La Sentinelle, et l'Ami des citoyens regardent cette réunion comme une dose d'opium et mettent le peuple sur ses gardes ».

Le rédacteur conclut : "L'avenir jugera », cette formulation apparemment prudente dissimulant en fait la certitude que de toute manière la

(31) Révolutions de Paris, dédiées à la nation et au district des Petits-Augustins, tome 13, $\mathrm{n}^{\circ} 157,14$ juillet 1792, p. 55 : l'auteur de l'article sur le « baiser Lamourette » précise en notes que « la section des Quatre-Nations a fait un repas en réjouissance de la réconciliation ».

(32) Maurice WAHL, Les premières années de la Révolution à Lyon (1788-1791), Paris, Armand Colin, 1894, p. 542.

(33) Le Patriote français, tome VI, $\mathrm{n}^{\circ} 1063,8$ juillet 1791, p. 29-30. Voici les phrases conclusives : «Qu'en doivent espérer les patriotes ? Ce n'est pas au milieu de la fermentation qu'il faut prononcer ; cependant on peut dire d'avance qu'elle contribuera à sauver la France, si on peut persévérer dans cette réunion jusqu'à ce que ses ennemis extérieurs soient vaincus; et si le pouvoir exécutif se joint de bonne foi à la bonne intelligence de l'Assemblée [...]. Mais si les perfidies continuent, si les hommes de bonne foi cherchent à en porter pour le malheur public, croyons-le, ils seront bientôt démasqués $[\ldots]$ ». 
liberté triomphera ${ }^{34}$. Ainsi, les réactions à court terme du baiser se rangeraient dans deux catégories : d'une part, ceux qui, à l'instar de Brissot et de ses amis, accueillent favorablement l'événement mais qui se montrent le plus souvent sceptiques, soucieux de la suite des événements; d'autre part, ceux qui ne tardent pas à dénigrer la scène et à accuser Lamourette de duplicité.

La presse de gauche apparaît divisée quant à l'interprétation à donner de l'événement. Tandis que le journal de Brissot accueille plutôt favorablement la scène de réconciliation, Dulaure, dans son journal $L e$ Thermomètre de Paris, met en doute que Lamourette soit le véritable inspirateur du discours du 7 juillet et en situe la source aux Tuileries ${ }^{35}$. L'argument selon lequel l'orateur serait affidé au parti de la cour revient de manière récurrente dans les jugements négatifs du «baiser Lamourette ». Le 8 juillet, dans son discours prononcé devant le Club des jacobins, Billaud-Varenne qualifie l'allocution de Lamourette d' " acte de machiavélisme » visant à protéger le parti royaliste de toute critique ${ }^{36}$. De même, les Révolutions de Paris, qui s'attardent longuement sur l'analyse de l'épisode, reprochent à Lamourette de « servir d'instrument à la cour » et d'utiliser la Constitution pour rétablir le « despotisme ». Ils le dénigrent férocement: «Car d'abord, pour peu qu'on connaisse le motionnaire, quel cas peut-on faire de la motion? », le présentant comme profondément influençable et malhonnête ${ }^{37}$. Le journal de Marat, l'Ami du peuple, quoique moins prolixe, campe également sur cette position. En conséquence, la majeure partie de la presse soutenant l'aile gauche de l'Assemblée se montre hostile à l'intervention de Lamourette, suspecté d'être de connivence avec la cour.

De son côté, l'Ami des patriotes propose, près de dix jours après les faits, une interprétation originale. Le «baiser» résulterait bien d'une manœuvre, non plus royaliste, mais « jacobite», fomentée dans l'entourage de M. de Sillery, lui-même proche du duc d'Orléans, afin de sauver

(34) Ibid., $\mathrm{n}^{\circ} 1064$, p. 33.

(35) Cité par Olivier Blanc, Marie-Olympe de Gouges. Une humaniste à la fin du XVIII ${ }^{e}$ siècle, s. 1., Éditions René Viénet, 2003, p. 168.

(36) Jean-Nicolas Billaud-Varenne, Réflexions de M. Billaud-Varenne, sur la séance du matin de l'Assemblée nationale du 7 juillet 1792, Paris, imprimerie du Patriote français, 1792, 6 p. Billaud-Varenne dresse le portrait d'un Lamourette suppôt de la Cour : « Car maintenant, s'entretenir des trahisons de la Cour, dévoiler ses manœuvres, avertir de ses complots, c'est se montrer anti-royaliste, c'est passer pour républicain, c'est mériter le titre de citoyen exécrable, d'après le pacte signé dans la séance d'hier. Je dis que depuis le début il n'y a pas eu d'astuce mieux combinée [...] ».

(37) Ibid., p. 50-51. 
Pétion. Le piège consisterait à profiter de l'enthousiasme suscité par la réconciliation générale pour amener le roi à contrer la décision du directoire du département et à révoquer la suspension du maire de Paris ${ }^{38}$.

Les autres journaux, de tendance modérée ou royaliste, oscillent entre la conviction de l'authenticité du «baiser » et la prudence face à l'effervescence suscitée. Le Journal général de M. Fontenai, plutôt favorable au maintien de la monarchie constitutionnelle, s'aligne sur la position de Condorcet, dont il cite longuement les propos : la Constitution doit être préservée, voire renforcée, mais selon une interprétation réactualisée, différente de celle du ministère feuillant de 1791. De même, le Journal de Paris, taxé de "contre-révolutionnaire» par les patriotes, soutient que le « baiser » ne cache nulle perfidie mais manifeste simplement que, grâce à Lamourette, érigé en héros, la vérité a été enfin reconnue par tous ${ }^{39}$. La Nouvelle correspondance politique, ou tableau de Paris, fermement royaliste, offre, quand à elle, une lecture qui entremêle l'image d'un roi paternaliste et providentiel : la réconciliation des « deux Partis » montrerait en effet que les députés, désorientés, s'en remettent au roi, « qu[i] les sauvera encore et de leurs propres fureurs, et de celles des puissances de l'Europe ${ }^{40}$. La Correspondance politique des véritables amis du roi et de la patrie $e^{41}$ et le Journal général de France ${ }^{42}$, plus prudents, hésitent entre l'espérance et le pessimisme.

De ce panorama de la presse se dégage un faisceau d'interprétations, parfois divergentes, $d u$ « baiser Lamourette ». L'événement intrigue les journalistes, tant dans son déroulement (comment les députés ont-ils pu céder à un tel enthousiasme ?) que dans ses motivations (Lamourette est-il une marionnette ou a-t-il agi de son propre mouvement ?).

Quelques témoignages permettent de saisir la réaction de la cour dans les jours suivant le « baiser ». Elle oscille d'abord entre désapprobation et espérance. Tandis que Gouverneur Morris, l'ambassadeur américain auprès de Louis XVI, " blâme » l'attitude du roi et reste fermement

(38) L'Ami des patriotes, ou le défenseur de la constitution, Paris, Demonville, nXVI, 16 juillet 1792, p. 189-191.

(39) Journal de Paris, $\mathrm{n}^{\circ} 190,8$ juillet 1792, p. 766-767.

(40) Nouvelle correspondance politique, ou tableau de Paris, pour servir de suite aux LII premiers numéros de la Correspondance politique des véritables Amis du Roi et de la Patrie, $\mathrm{n}^{\circ} \mathrm{XX}$ du 8 juillet 1792, p. 3.

(41) Correspondance politique des véritables amis du Roi et de la Patrie, $\mathrm{n}^{\circ} \mathrm{LXXI}, 10$ juillet 1792, p. 1-2.

(42) Journal de France, n 190, 8 juillet 1792, p. 758 : «L'effervescence est montée à un trop haut degré, et l'ébranlement trop universel, pour qu'on puisse espérer de voir cesser les haines et les divisions ». 
convaincu de la non-viabilité de la monarchie constitutionnelle, l'ambassadeur de Venise semble croire, du moins dans un premier temps, à la réalité de la réconciliation ${ }^{43}$. Puis les jugements s'homogénéisent. Ils rejoignent les opinions exprimées par la presse d'opposition, puisqu'ils qualifient l'épisode de ruse. Mais la responsabilité est ici principalement imputée aux jacobins. Lamourette n'est pas directement mis en cause. L'objectif du «baiser» demeure en revanche flou. Selon Marie-Antoinette, qui dès le 7 juillet 1792 exprime une profonde méfiance à l'égard des effusions des députés, les jacobins projetteraient de négocier avec le roi afin d'obtenir la signature de la paix et ainsi, conformément à la vision stratégique propre à la reine, de priver la famille royale du soutien apporté par les puissances étrangères ${ }^{44}$. De même, l'ambassadeur vénitien Amoro Pisani, dans la dépêche qu'il envoie au Conseil d'État le 9 juillet, une fois ses espérances évanouies, qualifie l'épisode du «baiser » de « farce» et souligne la difficulté à en percer les desseins, suspectant allusivement les jacobins ${ }^{45}$. Dans une lettre datée du 11 juillet, l'abbé Ratel, membre du réseau d'Antraigues, livre une analyse plus approfondie. D'après lui, Lamourette aurait été manipulé par Roederer et le ministre de la Justice Dejoly, dans le dessein d'accroître l'animosité de la « populace » à l'égard du parti royal auquel aurait pu profiter la récente suspension du maire de Paris $^{46}$. Le 13 juillet, la scène du «baiser Lamourette » est évoquée sous forme de chanson dans l'organe du parti royal, le Journal de la cour et de la ville. L'auteur joue sur l'homophonie du nom de l'orateur, orthographié tantôt «l'amourette », tantôt «Lamourette ». Ce recours à l'arme de la dérision et du ridicule, loin d'innover, reprend une rhétorique déjà employée lors de l'élection épiscopale de Lamourette. L'accent est placé ici sur le contraste entre l'intensité de la réconciliation et sa brièvetée ${ }^{47}$. Finalement, dans la semaine suivant le 7 juillet, les réactions négatives à

(43) Gouverneur Morris, Journal de Gouverneur Morris 1789-1792, Paris, Mercure de France, 2002, p. 350-351.

(44) Jean JAURĖs, Histoire socialiste de la Révolution française, Paris, Éditions sociales, 1970, tome II, p. 636.

(45) Alessandro Fontana et alii (dir.), Venise et la Révolution française. Les 470 dépêches des ambassadeurs de Venise au doge, 1786-1795, Paris, Robert Laffont, 1997, p. 758-759.

(46) Lettre de l'abbé Ratel à Choiseul-Beaupré (11 juillet 1792), reproduite dans Jacqueline Chaumié, Le réseau d'Antraigues et la Contre-Révolution (1791-1793), Paris, Plon, 1965, p. 193-194.

(47) «Chanson sur le baiser Lamourette », publiée dans le Journal de la Cour et de la Ville, 13 juillet 1792 ; puis reproduite par Albert Mathiez dans les Annales historiques de la Révolution française, 1925, tome II, p. 584. 
l'égard du «baiser Lamourette » tendent à dominer les quelques réceptions plus favorables.

Les écrits des contemporains, mémoires ou ouvrages à prétention historique, rédigés avec davantage de recul, de quelques mois à plusieurs années, offrent une interprétation plus dépassionnée de l'événement. Cependant, le débat reste identique : franchise ou simulation des protagonistes ? Certains auteurs, tels A.-F. Bertrand de Moleville ${ }^{48}$, se limitent à rapporter l'événement - souvent avec des inexactitudes -, retranscrivent éventuellement le discours de Lamourette mais sans émettre aucune opinion. D'autres, comme Alexandre, laissent transparaître leur position par l'emploi discret d'adjectifs ou d'adverbes ${ }^{49}$. Néanmoins la plupart des auteurs s'attardent sur leur perception, plus ou moins approfondie, de l'événement. Le marquis de Ferrières conclut laconiquement sa narration : «Il n'y eut aucune sincérité dans cet accord $»^{50}$. Au contraire, Toulongeon, ancien membre de la Constituante, l'avocat Hua, membre de la Législative, Claude-François Beaujeu et Roederer croient « ce rapprochement sincère » et expliquent son échec par la versatilité des passions et la pression des sentiments ${ }^{51}$.

Globalement, contrairement aux réactions immédiates, une image plutôt positive de l'événement se dessine sous la plume des contemporains. Le «baiser » est généralement perçu comme sincère en dépit de sa brièveté. Ce dernier caractère apparaît si prononcé qu'un écrivain anonyme en vient à le qualifier de « beau songe enfanté par une imagination douce et paisible $»^{52}$. Les auteurs s'interrogent davantage sur les réactions de l'assemblée que sur les motivations de Lamourette, qui ne pâtit donc pas d'un aussi mauvais portrait que celui qui s'impose peu après l'événement.

(48) Antoine-François Bertrand de Moleville, Histoire de la Révolution de France pendant les dernières années du règne de Louis XVI. $2^{\mathrm{e}}$ partie comprenant les années 1791, 1792 et 1793, jusqu'à la mort de Louis XVI inclusivement. Paris, Giguet et Michaud, 1902, tome VIII, p. 277-280.

(49) Jacques Godechoт, « Fragments des Mémoires d’Alexandre sur les journées révolutionnaires de 1791 et 1792 », Annales historiques de la Révolution française, 1952, p. 193.

(50) Mémoires du marquis de Ferrières, Paris, Baudouin fils, 1822, p. 142-144.

(51) François-Emmanuel ToulongeOn, Histoire de France, depuis la révolution de 1789, écrite d'après les mémoires et manuscrits contemporains, recueillis dans les dépôts civils et militaires, Paris, libraire Treuttel et Wûtrz et Didot Jeune imprimeur, 1801, tome II, p. 188-191 ; Eustache-Antoine Hua, Mémoires d'un avocat au parlement de Paris, député à l'Assemblée législative, Poitiers-Paris, 1871, p. 143 ; Claude-François BEAUlieu, Essais historiques sur les causes et les effets de la révolution de France, avec des notes sur quelques événemens et quelques institutions, Paris, Maradan, 1801-1803, vol. 3, p. 400-403 ; Pierre-Louis RoEDERER, Chronique de cinquante jours, du 20 juin au 10 août 1792, dans Euvres du comte de P.-L. Roederer, publiées par son fils, Paris, Firmin Didot, 1854, tome III, p. 141-142.

(52) Histoire de la Révolution de France..., op. cit., p. 64. 
La scène de réconciliation enclenchée par le discours de Lamourette, tour à tour perçue comme le baiser de Judas ou comme le baiser de paix selon les sympathies jacobines, constitutionnelles ou monarchistes, s'avère difficile à élucider. L'expression « baiser Lamourette » est finalement entrée dans le langage courant au XIX ${ }^{\mathrm{e}}$ siècle, comme désignant une réconciliation sincère, mais brève ${ }^{53}$. Contrairement à l'historiographie traditionnelle qui a plutôt insisté sur la ferveur des députés, il ne faut pas la dissocier des motivations personnelles de l'orateur.

\section{Une interprétation contradictoire : préserver puis renverser la Constitution}

Quels objectifs Lamourette vise-t-il en déclamant son discours le 7 juillet? Plus largement, de quelle façon introduire cette intervention dans la conduite politique générale qu'il adopte à la Législative ? L'interprétation varie selon le point d'ancrage chronologique du regard. Le flou qui l'auréole paraît entretenu par la volonté même de l'orateur. En effet, dans les deux mois suivant le baiser, il semble s'être ingénié à modifier l'image qu'il a donnée de lui-même le 7 juillet.

En regard des allocutions antérieures, son intervention du 7 juillet 1792 s'inscrit dans une continuité certaine. Son attachement à la Constitution s'avère un fondement de la conduite politique de Lamourette. Il transparaît nettement dans deux discours, le premier prononcé à Lyon le 25 septembre 1791 pour saluer l'adoption de la Constitution et le second à Paris le 4 décembre de la même année à l'occasion de la fête des canonniers volontaires. La Constitution, garante de la paix et de la liberté, est présentée aux fidèles de Rhône-et-Loire comme une clé ouvrant le chemin vers le bonheur ${ }^{54}$, idée, voire obsession qui hante sa pensée. Cette idée est approfondie lors du discours à Notre-Dame. Tandis que les menaces s'accroissent, Lamourette appelle avec insistance à l'union autour de la Constitution : "Voulons-nous rendre la constitution indestructible, rallions-nous tous autour d'elle, et ne connoissons qu'elle », puis plus loin, «La constitution, chers concitoyens, la constitution! que ce soit là notre cri de triomphe, et le centre de ce ralliement universel $\aleph^{55}$. Il précise les

(53) Le Courrier de Vaugelas, 1868-1869, $1^{\text {re }}$ année, p. 6.

(54) Adrien Lamourette, Discours prononcé par M. l'Évêque, Métropolitain du Département de Rhône-et-Loire, avant le Te Deum, chanté le dimanche 25 septembre 1791, à l'occasion de la Proclamation de la Constitution et de l'Empire, s. 1. n. d. [Lyon, 1791], p. 2-4.

(55) Id., Discours pour la Fête des Canonniers-volontaires de l'Armée Parisienne, prononcé en l'Église de Notre Dame, dimanche 4 décembre 1791, Lyon, Amable le Roy, [1791], p. 3-4. 
raisons de ce soutien. Il reprend les topoï du bonheur et de la liberté. Mais il évoque de surcroît la « régénération politique » et l'éloignement du «despotisme» qu'elle permet, ainsi que «l'égalité » qu'elle établit. Surtout il insiste sur la nature chrétienne des fondements de la Constitution, à savoir «tous les principes d'unité, de fraternité, d'égalité et de liberté, qui font la substance de ses lois ». Son plaidoyer en faveur de la Constitution s'enracine en fait dans l'idée qu'en une conjoncture marquée par un dénigrement quasi systématique de la religion, elle seule peut protéger le christianisme puisqu'elle s'inspire des préceptes évangéliques. Pour s'attirer des appuis politiques, il allègue donc que les adversaires du christianisme visent à terme un changement constitutionnel ${ }^{56}$. En dépit des dysfonctionnements de la Constitution, l'attachement de Lamourette au nouveau système politique ne faiblit pas. Dans un premier temps, il s'agit de fortifier le régime naissant, puis à partir de décembre 1791 et plus encore en juillet 1792, de le préserver. C'est dans ce dessein que l'évêque de Lyon lance des appels à une défense commune.

Les thèmes corollaires de l'union et de la réconciliation, omniprésents dans le discours du 7 juillet, occupent une place centrale dans l'ensemble de la production de Lamourette. Son apologétique se démarque par la mise en lumière des points de convergence avec la philosophie déiste et par des tentatives d'amorcer le dialogue avec ses représentants. Il développe un discours apologétique original. Comme nombre de contemporains, il cherche à se placer sur le terrain même de l'adversaire ; or il ne se contente pas de calquer les procédés stylistiques et linguistiques des philosophes mais il aborde de front leurs thèmes de prédilection, tels que le bonheur et la religion naturelle. Grâce à un renouvellement théologique et anthropologique, il permet l'insertion dans la pensée chrétienne de thématiques jusqu'alors surtout privilégiées par les philosophes. Sa volonté de conciliation est poussée fort loin : il propose aux philosophes d'aider à résoudre la crise que traverse le christianisme ${ }^{57}$. Mais cette attitude plutôt accommodante reste fidèle à la conception originelle de l'apologétique comprise comme discours de combat : elle vise à persuader de la vérité du christianisme.

(56) Ibid., p. 6: «Croyez donc, sages concitoyens, croyez que ceux qui s'appliquent à envelopper dans la masse des abus, à proscrire une religion si amie de la constitution, veulent toute autre chose que la constitution [...]».

(57) Adrien Lamourette, Pensées sur la Philosophie de l'Incrédulité, ou réflexions sur l'esprit et le dessein des philosophes irréligieux de ce Siècle, dédiées à Monsieur, Frère du roi, Paris, Chez l'Auteur, 1786, p. 224-226. 
Le désir de réconciliation guide également Lamourette dans son action épiscopale. De son arrivée à Lyon en avril 1791 à son départ pour Paris fin septembre, il ne cesse de minimiser les différences théologiques entre les constitutionnels et les réfractaires, d'insister sur leur appartenance commune à l'Église catholique, et de travailler à l'instauration d'un espace de neutralité, voire d'échanges. Puis à la Législative, il essaie d'aplanir les désaccords politiques et d'établir la Constitution comme point d'entente. Dans chacune des situations conflictuelles, il tente d'obtenir une conciliation entre les parties. Cette volonté de l'unité ne s'ancre-t-elle pas dans l'enseignement ecclésiastique, et particulièrement lazariste, qui lui a été professé ? En effet, Lamourette a reçu une formation de missionnaire et donc appris à manier la rhétorique de la réconciliation, « la pastorale du pardon et de la réconciliation » selon l'expression d'Alexandrette Bugelli ${ }^{58}$, utile lorsqu'en fin de mission, à l'issue de la confession générale, est entreprise la prédication de la réconciliation afin de dissoudre tous les désaccords. Ne peut-on voir dans le «baiser» une transposition de la rhétorique missionnaire de la réconciliation d'un contexte sacré à un cadre politisé et en voie de laïcisation, l'enceinte parlementaire ?

Le 7 juillet, loin de prêcher seul dans le désert, Lamourette apparaît comme le porte-parole d'une portion de l'opinion favorable au maintien de la Constitution mais qui, apeurée par la montée de la violence depuis la journée du 20 juin, resterait discrète. Son discours fait écho à des affiches placardées dans les rues de la capitale et invitant les députés à une réconciliation générale. Leur auteur, Olympe de Gouges, partie prenante de la guerre de propagande, essaie non seulement de peser sur l'opinion mais aussi sur les représentants de la nation, par l'envoi d'une longue lettre à la Législative le 4 juillet. Elle expose les mêmes idées que celles proclamées quelques jours plus tard par Lamourette. La lecture est cependant interrompue avant son terme à la demande de Merlin de Thionville, qui au nom de tous les républicains manifeste un fort mécontentement ${ }^{59}$. Le même jour, dans la séance du soir, lecture est faite d'une lettre, envoyée par le directoire du département des Ardennes, qui dresse un vibrant éloge de la Constitution et réclame la poursuite de tous « les factieux qui voudroient y porter atteinte $»^{60}$. Peut-être Lamourette a-t-il hâté la proclama-

(58) Alexandrette Bugelli, Vincent de Paul. Une pastorale du pardon et de la réconciliation. La confession générale, Paris, Cerf, 1997.

(59) Olivier Blanc, op. cit., p. 167-168. Précisons que l'auteur ne mentionne aucune relation entre Lamourette et Olympe de Gouges.

(60) Archives parlementaires, tome 46, p. 122. 
tion de son discours, dans l'espoir de profiter d'un courant d'opinion répercutant ses positions personnelles?

Ainsi, le discours du 7 juillet 1792 s'inscrit parfaitement dans sa ligne politique de défense inconditionnelle de la monarchie constitutionnelle, considérée comme le garde-fou de la religion catholique. Il corrobore même les accents conciliateurs qui imprègnent toute son œuvre antérieure. L'intervention du 10 juillet - dans le cas où l'attribution lui en est faite, et non à Damourette ${ }^{61}$-, loin de constituer un déni de sa prise de position antérieure, la confirmerait. Lamourette propose alors d'ajourner la déclaration de la patrie en danger, de crainte qu'elle ne provoque «l'anarchie » et la « guerre civile ». En effet, cette décision qui s'accompagnerait de l'adoption de mesures exceptionnelles et donc d'une application parcellaire de la Constitution accroîtrait davantage le risque d'un changement constitutionnel. Par cette allocution, Lamourette espère-t-il réellement faire renaître l'enthousiasme de ses collègues ou bien joue-t-il son ultime coup de dé en faveur de la monarchie constitutionnelle? En tout cas, son initiative échoue. Le lendemain, le décret de la patrie en danger est voté.

Habituellement plutôt effacé, Lamourette réclamerait la parole deux fois en l'espace de quatre jours dans le but de sauvegarder la monarchie constitutionnelle. Quoique ces prises de position soient moins motivées par la volonté de préserver le roi que par le souhait de conserver une Constitution qui instaurerait une régénération politique et religieuse, l'image d'un Lamourette partisan de la cause royale s'impose pourtant comme le révèle l'affaire Casati ${ }^{62}$ qui éclate à Lyon en août 1792 . Fervent royaliste, Thomas Nicolas Casati projette d'assassiner le maire de Lyon, Louis Vitet, qu'il considère comme un ennemi de la monarchie. Il écrit à Lamourette à deux reprises, le 7 puis le 17 août, afin de lui demander son

(61) L'emploi du conditionnel est justifié ici par l'attribution très incertaine de cette intervention à Lamourette. La mauvaise qualité du papier de la minute relatant cet épisode empêche de confirmer ou d'invalider toute hypothèse. En effet, le papier est « mangé » précisément à l'endroit où figure le nom de l'orateur (AN, C 153, f 272 ). L'hypothèse selon laquelle Lamourette serait bien l'auteur de ce discours est alimentée par l'Histoire parlementaire de la Révolution française..., op. cit., tome 15, p. 357, et la Réimpression de l'Ancien moniteur..., op. cit., tome 13, p. 107, qui indiquent toutes deux le nom de Lamourette comme orateur. De plus, dans sa Chronique de cinquante jours, op. cit., p. 142-143, Roederer note que c'est bien l'évêque de Rhône-et-Loire l'auteur du discours. Mais l'hypothèse inverse, selon laquelle Damourette prononcerait ce discours, peut s'appuyer sur les Archives parlementaires, tome XLVI, p. 311-312, qui indiquent bien ce dernier, député des Ardennes, comme orateur. Roy, 1792.

(62) Au citoyen directeur du juré d'accusation près le tribunal de Lyon, Lyon, Amable Le 
concours. Ce dernier ne semble pas lui avoir répondu mais communique la lettre à la municipalité de Lyon. Casati est arrêté et emprisonné. Pourquoi avoir choisi Lamourette ? Casati s'adresse à un personnage important de la vie lyonnaise du fait de sa dignité épiscopale, dont l'influence est même devenue nationale grâce à son mandat parlementaire, et qui de surcroît - aspect non négligeable pour un partisan de Louis XVI - s'est récemment illustré par ses prises de parole en faveur de la sauvegarde de la monarchie constitutionnelle.

Certes, cette image d'un Lamourette défenseur du parti royal est démentie par son refus d'apporter son aide. Cette anecdote montre cependant que l'épisode du baiser a modifié le regard généralement jeté par les contemporains sur Lamourette : auparavant plutôt rangé au centre, dans le Marais, il tend à être classé parmi l'aile droite de l'Assemblée, les feuillants. Durant le mois d'août et surtout au début de septembre, il travaille à corriger cette représentation, en la teintant de « jacobinisme ». L'interprétation qu'il livre a posteriori du « baiser» s'oppose alors complètement à la vision qui se dégage au vu de son action parlementaire antérieure.

La publication de la Réponse à M. l'abbé Molin révèle les efforts, sinon la stratégie, déployés par Lamourette pour réhabiliter son image dans un contexte défavorable aux partisans de la monarchie constitutionnelle. Ce document désigne en fait une lettre qu'il a rédigée le 29 août à l'adresse de son vicaire et ami, l'abbé Molin, puis publiée le 7 septembre suivant. L'éditeur explique brièvement en avant-propos les raisons de cette impression : effacer la «cruelle calomnie [qui] a semé ses poisons dans les esprits contre M. Lamourette », présenté comme " essentiellement trop honnête homme et trop excellent patriote, pour être dans le cas d'attendre les bons offices d'un défenseur ». Cet écrit constitue donc un plaidoyer en faveur de l'évêque de Rhône-et-Loire. Or, dans son diocèse, la scène de réconciliation du 7 juillet a surtout suscité des réactions sceptiques, voire hostiles. Bien accueillie par le directoire du département, elle a été en revanche rejetée par les districts et les municipalités, et férocement décriée dans le Journal de Lyon qui s'est attaqué ad hominem à Lamourette en le qualifiant de «poupée parlante » au service de la cour et des traîtres ${ }^{63}$.

(63) Maurice WAHL, op. cit., p. 544. Sur le contexte religieux lyonnais voir Paul CHOPELIN, Ville patriote et ville martyre. Une histoire religieuse de Lyon pendant la Révolution (1788-1805), thèse de doctorat sous la dir. de Bernard Hours, Université Lyon 3 Jean Moulin, 2006, 2 vol. 
Dans ce contexte, la Réponse... est à lire comme une tentative de réhabiliter sa réputation. Probablement est-il accusé par les jacobins lyonnais de côtoyer des « conventicules feuillants », puisque dans sa lettre il se défend avoir fréquenté des députés feuillants notamment lors des « dîners civiques » qu'il organisait. Au contraire, il affirme n'avoir « jamais eu de relations qu'avec les députés notoirement dévoués à la cause du peuple, et avec les écrivains les plus célèbres pour leurs ouvrages révolutionnaires ». Il mentionne parmi ses relations Cloots et Champagneux alors appréciés des jacobins, l'un figurant comme un concepteur précoce de la république, le second travaillant au gouvernement dans l'ombre du ministre de l'Intérieur, Roland. Son objectif est de clamer sa parenté avec les jacobins en dépit d'une adhésion de pure forme à leur société mère. À cette fin, Lamourette revient sur le sens et la généalogie du baiser. Il présente cet épisode non comme une tentative de freiner la chute de la monarchie constitutionnelle, mais au contraire un moyen de mettre un terme à une situation politique confuse : "Cette réunion est [considérée comme] l'une des causes qui ont précipité la chute du 10 [août] » et aidé à l'avènement de la République. Dans cette perspective, il commence par déplorer que la scène de réconciliation du 7 juillet ait été mal interprétée, et ait « si efficacement servi les vues de l'injustice qui me poursuit $»^{64}$. L'intervention aurait en fait été concertée avec trois ou quatre députés, parmi lesquels Delaunay d'Angers proche des brissotins ${ }^{65}$ - cet argument permettant à Lamourette de se dédouaner de l'entière responsabilité de cette initiative ${ }^{66}$. Elle visait en fait à « démasqu[er] toutes les conspirations des Tuileries, et toute l'hypocrisie des prétendus Constitutionnels ${ }^{67}$. Initialement, Lamourette explique avoir voulu demander la suspension de la Constitution car, selon lui, elle est dévoyée par le roi à une fin contre-révolutionnaire :

« Je pensois depuis longtemps en moi-même, que la constitution devenoit de plus en plus, dans les mains du roi et de ses agens pervers, un instrument de contre-révolution, et que rien n'étoit plus absurde et plus superstitieux

(64) Adrien Lamourette, Réponse à M. l'abbé Molin..., op. cit., respectivement p. 13 et p. 10.

(65) Mémoires et notes de Choudieu, représentant du peuple à l'Assemblée législative, à la Convention et aux armées (1761-1838), Paris, Plon, 1897, p. 226 : Delaunay d'Angers est présenté comme très lié avec les principaux membres de la « Gironde », et décrit comme un orateur éloquent mais de caractère faible.

(66) Adrien Lamourette, Réponse à M. l'abbé Molin... op. cit., p. 11, puis p. 13 : Lamourette explique qu'il aurait anticipé une intervention de Hérault de Séchelles favorable à la suspension de la Constitution, prévue pour le 9 , mais trop tardive à son goût.

(67) Ibid., p. 12. 
en politique, que de s'assujettir littéralement à une constitution, lorsqu'un État est encore en pleine révolution. J'ai écrit mes idées sur cette matière, et je concluois à ce que le corps législatif, jusqu'après la clôture définitive de la révolution, fermât le livre de la constitution, et ne consultât, dans ses déterminations, que la loi éternelle et suprême du salut du peuple $»^{68}$.

Delaunay s'est fait le porte-parole d'un tel projet. Mais les partisans du « comité autrichien » et des députés crédules, croyant encore en l'honnêteté du roi, se sont opposés suffisamment nombreux pour faire échouer l'idée. La stratégie a donc consisté ensuite à prononcer un discours en faveur de l'union autour de la Constitution, afin de contraindre à sa suspension en cas de violation d'une de ses deux parties, en l'occurrence du roi, puisque l'Assemblée, par son serment, avait promis solennellement de la maintenir ${ }^{69}$. D'après cette nouvelle lecture, des sentiments bas, sinon immoraux, tels que le cynisme et l'hypocrisie, constitueraient les ressorts du « baiser Lamourette », orchestré non par le seul évêque de Rhône-etLoire mais par un véritable clan.

Cette interprétation paraît-elle plausible ou bien serait-elle reconstruite, sinon totalement du moins en partie ? La sincérité de Lamourette peut être mise en doute. En effet, le contexte laisse penser qu'il est en proie à une peur quasi continuelle. À Paris, le 10 août a permis l'instauration d'une commune insurrectionnelle qui détient désormais la réalité du pouvoir. Dans l'attente de l'ouverture de la Convention, la Législative se contente de gérer les affaires courantes. Les députés qui manifestent leur désaccord sont conspués. Lamourette connaît alors la crainte au quotidien. De surcroît, à Lyon où il devra bientôt revenir à l'issue de son mandat parlementaire, la situation ne se présente guère mieux. Le sentiment de peur qu'il ressentait avant même son départ pour la capitale en septembre 1791 a probablement empiré. Il explique son besoin de justifier son intervention du 7 juillet et de se ranger dans le camp désormais au pouvoir. Lamourette aurait donc rédigé la lettre à l'abbé Molin dans la perspective d'une publication. Le fait de la destiner à un ami, et non à une administration telle que la municipalité ou à un organe de presse, permet de jouer sur l'affect et de mettre en avant la sincérité de l'auteur. Mais la volonté de

(68) Ibid., p. 9.

(69) Ibid., p. 11-12 : «Rallions, s'il est possible, tous les partis de la représentation nationale autour de la constitution, puisqu'on ne peut s'apprivoiser avec l'idée d'en interrompre l'observation, afin que toute la France sache qu'il n'a pas tenu à ses représentans qu'elle ne fût maintenue, et que sa chute ne sauroit jamais être que l'ouvrage de ceux qui ne la préconisent que par ce qu'elle leur sert à tuer la liberté. ». 
s'attacher la confiance des révolutionnaires favorables à la République peut également s'appuyer sur une véritable conviction. Elle s'enracinerait alors dans une conversion, sinon de cœur, du moins de raison, à ce nouveau régime, face au constat de l'impossibilité d'une monarchie constitutionnelle viable à l'issue de la journée du 10 août. L'influence de Cloots aurait pu faciliter cette adhésion.

Aussi, en fonction du repère chronologique choisi, la scène de réconciliation du 7 juillet peut-elle faire l'objet de deux lectures contrastées. Considéré dans le prolongement de l'action politique antérieure au 7 juillet 1792, le « baiser » est compris comme l'ultime tentative, inspirée par la sincérité, de créer une union nationale et de sauver une monarchie constitutionnelle garantissant une régénération religieuse et politique fidèle à l'Évangile. Peut-être son auteur profite-t-il des sentiments d'unanimité que ravive l'approche de la fête de la Fédération du 14 juillet. En revanche, un mois et demi plus tard, au regard de la lettre de Lamourette adressée à Molin et plus largement aux « jacobins lyonnais », l'épisode s'offre à lire comme un acte cynique et perfide, visant à provoquer l'affrontement qui devra enfanter le régime républicain. L'orateur, en proie à la peur, en vient donc à reconstruire un passé récent devenu gênant.

À quel moment s'effectue cette distorsion de la représentation entre un baiser de paix et un baiser de Judas ? Probablement dans la deuxième quinzaine d'août. En effet, le 14 août, Lamourette prononce un discours devant la Société nationale des neuf sœurs, héritière de la très prestigieuse Loge des neuf sœurs ${ }^{70}$. Il presse les gens de lettres de se servir de leur plume pour clore la Révolution ${ }^{71}$. Il les investit d'une sorte de mission religieuse : les écrivains endossent le rôle de rédempteurs, à charge pour eux de sauver les acquis révolutionnaires, d'enrayer la radicalisation du mouvement parisien et d'assurer le bonheur de l'humanité. Ce discours du 14 août se situe dans le prolongement de l'allocution du 7 juillet. Dans les deux cas, Lamourette appelle à un arrêt des violences et à une stabilisation de la Révolution, son objectif étant de préserver l'alliance entre le christianisme et la Révolution.

(70) Louis Amiable, Une loge maçonnique d'avant 1789 : la Loge des Neufs Scurs, augmenté d'un commentaire et de notes critiques de Charles Porset, Paris, Félix Alcan, 1989, p. 79 et suivantes. La filiation entre la Loge des Neuf Sœurs et la Société du même nom a fait l'objet de controverses. Charles Porset affirme une continuité certaine en constatant entre elles une identité d'objectifs et de personnel, p. 82.

(71) Adrien Lamourette, « Sur les devoirs des gens de lettres envers leurs concitoyens, dans les temps de révolution », Extrait du Tribut de la Société-Nationale des Neuf Sœurs. 14 août 1792, Paris, de l'imprimerie de la Société Nationale des Neuf Sœurs, 1792. 
Son attitude a totalement changé le 29 août. Il apporte alors clairement son soutien aux partisans de la République. Le jour même de la rédaction de sa lettre de justification à Molin, il monte à la tribune pour critiquer une brochure royaliste qui tourne en ridicule l'Assemblée et qui présente le couple royal sous « l'image de l'innocence et de la vertu opprimées ». Il dénonce une « conspiration aristocratique », que favorisent « la cohabitation de Louis XVI avec sa famille » et plus précisément les communications établies par Marie-Antoinette avec les émigrés de Coblence. Il conclut en demandant qu' « il soit décrété que le roi et les différentes personnes de sa famille n'auront plus de communication entre elles $»^{72}$. La motion de Lamourette n'obtient aucune répercussion puisque la décision relève non de la Législative mais de la municipalité parisienne qui a en charge la surveillance de Louis XVI et de sa famille emprisonnés au Temple depuis le 10 août. Cette intervention montre qu'à la fin août 1792, Lamourette ne croit plus en la viabilité de la monarchie constitutionnelle. Pour la première fois, il dresse un portrait fort dépréciatif de Louis XVI, en insistant sur sa « lourde nullité ». Il laisse transparaître la responsabilité directe du roi dans la faillite de la monarchie constitutionnelle. L'intervention du 29 août est à lire comme l'étape ultime de son ralliement à la République.

Dans la deuxième quinzaine d'août, Lamourette passe donc de la dénonciation des dérives de la Révolution au lendemain du 10 août, à une adhésion de raison au régime républicain, affirmée le 29 août. Ce changement politique se traduit dans ses discours : la rhétorique de la conciliation fait place à la rhétorique de l'affrontement. Vraisemblablement, c'est moins une conviction idéologique solidement ancrée que la conscience de la faillite de la monarchie constitutionnelle et le souci de défendre le statut du christianisme au sein de la nouvelle organisation politique qui motivent la conversion de Lamourette à la République.

Le « baiser Lamourette », du moins tel que son auteur le concevait lors de l'énonciation de son discours, c'est-à-dire comme un baiser de paix, apparaît bien emblématique du personnage. Toute sa vie, tant dans ses fonctions de directeur de séminaire que d'apologiste, d'évêque constitutionnel ou de député, il s'est attaché à réconcilier les irréconciliables, et plus, à rallier tout le monde à son idée de bonheur. Cette volonté d'unité peut s'enraciner non seulement dans la pastorale lazariste de réconciliation, mais aussi dans l'obsession d'unité qui caractérise tout le XVIII siècle,

(72) Pierre-Célestin Roux (dir.), op. cit., tome 17, p. 143-144. 
lequel croit encore à une conception holiste de la société, et dans le modèle chrétien d'unité organisée à partir du Christ.

Le souvenir du «baiser» suit son initiateur jusqu'à ses derniers instants. Arrêté à la fin du siège de Lyon le 29 septembre 1793, puis transféré le 8 octobre à Paris pour être jugé par le Tribunal révolutionnaire, Lamourette reçoit sa sentence le 11 janvier 1794 (22 nivôse an II). Alors accusé d'être « contre-révolutionnaire » au motif de sa collaboration avec Mirabeau et du soutien apporté aux "fédéralistes» lyonnais, il est condamné à mort et exécuté le jour même. Selon le bourreau, CharlesHenri Sanson, lorsqu'il monte sur l'échafaud, les spectateurs lui crient : «Baise Charlot [Sanson], Lamourette; allons, baise Charlot!». Et Lamourette, fidèle à son obsession de réconciliation, de répondre : «Oui, j'embrasserai en toi l'humanité qui, si folle et si furieuse, est toujours l'humanité $\|^{73}$.

Caroline Chopelin-Blanc

RESEA - UMR 5190, LARHRA Institut d'histoire du Christianisme Université Jean Moulin - Lyon 3 18 rue Chevreul 69007 Lyon Chopelinblanc@aol.com

(73) Henri Sanson (éd.), Sept générations d'exécuteurs (1688-1847). Mémoires des Sanson, Paris, Dupray de La Mahérie, 1863, tome IV, p. 386-387. Ce témoignage est sujet à caution. Il n'est corroboré ni par les rapports de Letassey, ni par ceux de Charmont (Pierre CARON (éd.), Paris pendant la Terreur. Rapport des agents secrets du ministre de l'Intérieur, Paris, Picard, 1914, volume 2, p. 300 et p. 308-309), ni même par Georges Duval (Souvenirs de la Terreur de 1788 à 1793, Paris, Werdet, tome IV, p. 193). 